\section{Newborn Screening by Tandem Mass Spectrometry}

\author{
Ethical and Social Issues
}

\author{
Denise Avard, $\mathrm{PhD}^{1}$ \\ Hilary Vallance, $\mathrm{MD}^{2}$
}

\author{
Cheryl Greenberg, $\mathrm{MD}^{3}$ \\ Beth Potter, $\mathrm{PhD}^{4}$
}

\title{
ABSTRACT
}

Emerging technologies like Tandem Mass Spectrometry (TMS) enable multiple tests on a single blood sample and allow the expansion of Newborn Screening (NBS) to include various metabolic diseases. Introducing TMS for NBS raises important social and ethical questions: what are the criteria for adding disorders to screening panels? What evidence justifies expansion of screening? How can equity in NBS access and standards be ensured? How can policy standards be set, given the multiplicity of stakeholders?

To address emerging issues, policy-makers, patient advocates, clinicians and researchers had a workshop during the 2005 Garrod Symposium. The participants received a summary of the discussion and understood the workshop's goal was to provide a basis for further discussion. This article contributes to this ongoing discussion.

Several proposed recommendations assert the centrality of including social and ethical issues in the assessment of whether or not to introduce TMS. The article outlines five key recommendations for advancing the NBS agenda: national public health leadership; transparency; increased national consistency in NBS strategy, including minimum standards; collaboration between the federal and provincial/territorial governments and diverse stakeholders; and supporting research and/or programs based on effectiveness, which integrate ethical and social issues into assessment.

MeSH terms: Neonatal screening; ethics; health policy; mass spectrometry

\section{RÉSUMÉ}

L'émergence de nouvelles technologies comme la spectrométrie de masse en tandem (MS/MS) permet d'effectuer plusieurs tests sur un même échantillon sanguin, ce qui accroît la portée du dépistage néonatal (DNN). L'utilisation de la MS/MS dans le cadre du DNN soulève d'importants enjeux sociaux et éthiques. Quels sont les critères permettant l'ajout de maladies aux programmes de dépistage? Comment justifier l'expansion du dépistage? Comment assurer l'équité de l'accès et des normes en matière de DNN? Comment élaborer des politiques normatives, étant donné la multiplicité des parties intéressées?

Des décideurs, des défenseurs des droits des patients, des cliniciens et des chercheurs ont participé à un atelier lors d'un symposium organisé par la Garrod Association en 2005. Les participants ont reçu un résumé des débats et ont compris que l'atelier, tout comme le présent article, jetterait les bases d'une discussion ultérieure.

Il est important d'inclure les enjeux sociaux et éthiques dans l'évaluation de l'utilisation de la MS/MS. Cet article expose cinq recommandations-clés concernant le DNN : leadership national en santé publique; transparence; uniformité des stratégies nationales, incluant des normes minimales; collaboration entre les gouvernements et les parties intéressées; et soutien à la recherche et/ou aux programmes efficaces qui tiennent compte des enjeux sociaux et éthiques.

1. Centre de recherche en droit public, Université de Montréal, Montréal, QC

2. Hospital Newborn Screening Program of British Columbia, University of British Columbia, Vancouver, BC

3. Department of Biochemistry \& Medical Genetics and Department of Pediatrics \& Child Health, University of Manitoba, Winnipeg, MB

4. Department of Epidemiology and Community Medicine, University of Ottawa, Ottawa, ON Correspondence and reprint requests: Dr. Denise Avard, Centre de recherche en droit public, Université de Montréal, C.P. 6128, succ. Centre-ville, Montreal, QC H3C 3J7, Tel: 514-343-7702, Fax: 514-343-6233, E-mail: denise.avard@umontreal.ca

Acknowledgements: We thank Margo Plant, Centre de recherche en droit public, Université de Montréal, for her valuable work preparing the initial summary of the meeting. This study was funded by the Canadian Institutes of Health Research, application number 116301.

$\mathrm{N}$ ewborn screening (NBS) using dried blood spot collection cards identifies high-risk infants for whom treatment could improve health and quality of life. ${ }^{1}$ For example, early identification of high phenylalanine levels allows treatment of phenylketonuria (PKU) through diet, preventing lifelong, severe mental disability.

Emerging technologies like Tandem Mass Spectrometry (TMS) enable multiple tests on single blood samples and allow NBS expansion to include various metabolic diseases. At least 30 metabolic disorders are detectable in blood collected on conventional NBS cards through the standard heel-prick method. ${ }^{2}$ However, for many, it is unclear whether early intervention improves clinical outcomes. Thus, introducing TMS for NBS raises social and ethical questions: what are the criteria for adding disorders to screening? What evidence justifies expansion of screening? How can equity in NBS access and standards be ensured? How can policy standards be set, given the multiplicity of stakeholders?

To address emerging ethical and social issues related to NBS with TMS, policymakers, patient advocates, clinicians, and representatives from provincial NBS programs and governmental and nongovernmental organizations were invited to Ottawa in May 2005 for the Garrod Symposium, "The Application of Technologies for the Study of Inborn Errors of Metabolism" (http://www.garrod.ca/subpages/2005_agm.htm). Also present were academics studying law, ethics, sociology, and evidence-based medicine. The participants were told the report summary would be sent to them and submitted to the Garrod Association.

This article first summarizes various countries' current positions on using TMS and then focuses on the ethical and social questions identified during the workshop.

\section{Overview of NBS standards using TMS}

NBS standards vary both between and within countries; the variation is accentuated by differences in decisions regarding TMS implementation. For example, the United States has no federal guidelines about which disorders to include in NBS programs. Recently, the American College of Medical Genetics (ACMG) extensively 
reviewed NBS test panels, developing uniform national guidelines: it recommended screening 29 core conditions. ${ }^{3}$ Some experts, concerned the report has serious flaws, have published cautions that these recommendations are biased due to methodological problems. ${ }^{4}$

Australia has federal guidelines advocating NBS for PKU, congenital hypothyroidism $(\mathrm{CH})$, and cystic fibrosis $(\mathrm{CF})$ and recommending screening for other conditions, including $30+$ metabolic disorders detected using TMS. ${ }^{5}$ The United Kingdom has universal NBS for PKU and $\mathrm{CH}$ and is currently implementing it for $\mathrm{CF}$ and sickle cell disease. ${ }^{6} \mathrm{~A}$ pilot study of screening for medium-chain acyl-CoA dehydrogenase deficiency (MCADD), a TMS-identifiable metabolic condition, is underway. ${ }^{6}$

Within Canada, provinces determine the disorders included in NBS (in the territories, NBS is covered by adjacent provinces), ${ }^{2}$ which is delivered primarily as a public health program. The number of conditions on current panels ranges from 3 (Quebec) to nearly 30 (Saskatchewan) with all programs screening for PKU and $\mathrm{CH}$ at a minimum. ${ }^{2}$ TMS was implemented in British Columbia with the addition of MCADD; Nova Scotia added several TMS disorders, and Saskatchewan, the full TMS panel. TMS is also being implemented in Manitoba and Alberta, while Ontario recently announced 25 additions, 19 of which will use TMS screening. ${ }^{7}$

\section{Social and ethical issues}

The workshop addressed ethical issues surrounding the implementation of policy regarding TMS in NBS. This commentary discusses four themes.

\section{NBS Standard: Criteria for Adding Disorders}

Traditionally, NBS programs were limited to diseases for which early detection and treatment offer direct medical benefit to the affected child. While the World Health Organization's (WHO) 1960s criteria have been the gold standard, ${ }^{8}$ their interpretation and appropriateness have been increasingly questioned. One WHO screening criterion is treatability. Because TMS technology can be used in screening clinically significant but non-treatable disorders or disorders which have treatment of unknown health benefit, it appears the criterion's definition of "health benefit" has been broadened to include the "benefit" to parents and, potentially, to the child of an earlier diagnosis: namely, knowing what symptoms the infant will develop and why.

Another WHO criterion is that the screened condition be an "important health problem," 8 in severity and prevalence. Some critics challenge the usefulness of a criterion for NBS using TMS that specifies high disease prevalence since most screenable inherited metabolic conditions are rare. Still, they can be screened simultaneously and are collectively of public health importance.

Overall, there is no consensus whether screening should remain focused on conditions with treatments offering improved clinical outcomes for the child or whether it should balance benefits to the family against potential harms, like parental anxiety due to false positives or harms from diagnoses with uncertain clinical courses. ${ }^{9}$

\section{Evidence in Establishing the Benefits and Harms of NBS}

With the diminishing cost of expanding screening panels, there will be increased pressure to include disorders with unproven, marginal, or non-existent medical benefits from early diagnosis for the newborn. While the decision to include a disorder should be based on rigorous research about the effectiveness of screening - not merely on its low cost - there is often insufficient evidence to evaluate the utility of screening for particular disorders, in terms of both clinical benefits/harms and familial repercussions. This hurdle will be difficult to overcome: generally, the evidentiary basis for NBS programs is lacking, ${ }^{10,11}$ primarily because many metabolic conditions are rare; randomized trials of NBS programs for rare disorders are problematic, both methodologically (inadequate sample sizes; feasibility of long-term follow-up) and ethically (treatment of uncertain benefit may be perceived as preferable to no treatment, raising concerns about denying screening to subgroups of infants in studies). Also, knowledge about the natural history of many disorders is lacking.

Thus, the ACMG's position supporting all possible screening ${ }^{3}$ using TMS has been criticized by evidence-based medicine experts who claim the review methodology was seriously flawed. ${ }^{4}$ In contrast, the UK adopted a more rigorous approach to examine research evidence associated with TMS, recommending screening for MCADD only. MCADD met the criterion of "obvious health benefit"; other disorders on the TMS test panel (except PKU, which is already part of NBS) did not. ${ }^{6}$

The Ottawa workshop participants suggested that organizations like the Canadian Coordinating Office for Health Technology Assessment and the Canadian Institutes of Health Research should help further the assessment of TMS in Canada so that NBS program implementation is informed by evidence rather than opinion.

\section{Equity of Access to NBS Programs}

NBS programs are complex. They require laboratories, clinical referrals, timely followup, staff (including genetic counsellors), and facilities for program management and education. ${ }^{12,13}$ During periods of fiscal restraint, such programs may be underfunded, possibly leading to differences in accessibility: depending on their province of birth, babies may not have access to screening or related services. Many participants had difficulty understanding why some provinces test for two disorders (PKU and $\mathrm{CH}$ ) while others, like Saskatchewan and Ontario, test for 27+, and believed there should be minimum standards for conditions being screened.

\section{The Policy Process: A Public Process}

Increasingly, policy-makers realize that to confront difficult policy questions, they must address the views of multiple stakeholders. Including stakeholders is highlighted as a means of promoting transparency and ethics in decision-making about screening policies. ${ }^{14}$ There is also growing emphasis on ensuring that socioethical and legal issues are adequately considered to facilitate fairness in decisionmaking and, ultimately, to lead to decisions that represent community values. While recognizing the importance of federal/provincial/territorial cooperation and of our universal health care system, Canadian policy-makers also recognize the need to include representatives of parents, public interest groups, health care providers (e.g., the Canadian Paediatric Society, the 
Garrod Association), researchers, and government agencies like the Public Health Agency of Canada to shape the policymaking process. ${ }^{2}$ A public process to advise on these difficult and controversial questions is crucial.

\section{Future policy directions}

In this era of genomic knowledge ${ }^{15}$ and community involvement in policymaking, ${ }^{12,16,17}$ it is necessary to re-examine Canadian NBS programs in light of social and ethical concerns. As more provinces introduce or examine TMS usage, we recommend the following to advance the NBS agenda:

- National public health leadership should be established and maintained to support ongoing Canadian NBS policy development addressing the integration into provincial programs of TMS and other emerging technologies;

- Provinces should have clear, transparent processes for determining which disorders to include in NBS programs;

- To increase national consistency, a national NBS strategy, including minimum standards, should be developed;

- The development of the national NBS strategy should involve collaboration between federal and provincial/territorial governments and diverse stakeholder groups;

- The national NBS strategy should include the establishment and support of research priorities and programs to ensure NBS policies are based on effectiveness and to ensure ethical and social issues are integrated into the assessment. Concrete steps are necessary to advance this issue and transform discussion into action. The workshop was useful in generating ideas. Essentially, participants felt a national process is necessary for NBS policy development. Because socio-ethical-legal issues are inherent in NBS policy, a purely technical or scientific analysis of the issue is inadequate. Therefore, in addition to augmenting scientific evidence through research, it is necessary to assess what is acceptable to the Canadian public. Wide participation should be encouraged so that the re-evaluation of existing screening criteria conforms with and responds to the needs and values of Canadians.

\section{REFERENCES}

1. Pollitt RJ, Green A, McCabe CJ, Booth A, Cooper NJ, Leonard JV, et al. Neonatal screening for inborn errors of metabolism: Cost, yield and outcome. Health Technol Assess 1997;1(7): i-202.

2. Hanley WB. Newborn screening in Canada Are we out of step? Paediatrics Child Health 2005;10(4):203-7.

3. American College of Medical Genetics. Newborn Screening: Toward a Uniform Screening Panel and System. Rockville, MD: Maternal and Child Health Bureau, Health Resources and Services Administration, U.S. Department of Health and Human Services, 2005. Available online at: http://mchb.hrsa.gov/screening/ (Accessed June 20, 2007)

4. Botkin JR, Clayton EW, Fost NC, Burke W, Murray TH, Baily WA, et al. Comment on: $A$ Report of the American College of Medical Genetics. Report titled Newborn Screening: Toward a Uniform Screening Panel and System. Submitted as public comment. Available for inspection at Maternal and Child Health Bureau/Health Resources and Services Administration Office, Rockville, MD, 2005.

5. Human Genetics Society of Australia (HGSA), Royal Australian College of Physicians (RACP), Newborn Screening Joint Subcommittee. HGSA policy statement 2004: Newborn blood-spot screening. 2004. Available online at: http://hgsa.com.au/images/UserFiles/Attachments/ hgsapolicystatementnewbornscreening 020418.03.pdf (Accessed June 20, 2007).

6. UK Newborn Screening Program Centre. Newborn blood spot screening in the UK.
Policies and standards. United Kingdom: UK Newborn Screening Program Centre, 2005. Available online at: www.newbornscreeningbloodspot.org.uk (Accessed June 20, 2007).

7. Ontario Ministry of Health and Long-Term Care. Backgrounder: McGuinty government expands newborn screening program. 2005 Available online at: http://www.health.gov.on.ca/ english/media/news_releases/archives/nr_06/nov/ nr_112306.html (Accessed June 20, 2007).

8. Wilson JMG, Junger G. Principles and Practice of Screening for Disease. Geneva, 1968. Report No. 34.

9. Waisbren SE, Albers S, Amato S, Ampola M, Brewster TG, Demmer L, et al. Effect of expanded newborn screening for biochemical genetic disorders on child outcomes and parental stress. JAMA 2003;290(19):2564-72.

10. Pandor A, Eastham J, Beverley C, Chilcott J, Paisley S. Clinical effectiveness and cost-effectiveness of neonatal screening for inborn errors of metabolism using tandem mass spectrometry: A systematic review. Health Technol Assess 2004;8(12):iii, 1-iii121.

11. Seymour CA, Thomason MJ, Chalmers RA, Addison GM, Bain MD, Cockburn F, et al. Newborn screening for inborn errors of metabolism: A systematic review. Health Technol Assess 1997;1(11):i-95.

12. McCabe LL, Therrell BL, Jr., McCabe ER. Newborn screening: Rationale for a comprehensive, fully integrated public health system. Mol Genet Metab 2002;77(4):267-73.

13. American Academy of Pediatrics. Serving the Family From Birth to the Medical Home. A Report From the Newborn Screening Task Force Convened in Washington, DC, May 10-11, 1999. Pediatrics 2000;106(2 Pt 2):383-427.

14. Hiller EH, Landenburger G, Natowicz MR. Public participation in medical policy-making and the status of consumer autonomy: The example of newborn-screening programs in the United States [see comments]. Am I Public Health 1997;87(8):1280-88

15. Therrell BL, Jr. U.S. newborn screening policy dilemmas for the twenty-first century. Mol Genet Metab 2001;74(1-2):64-74

16. Hofmann B. Toward a procedure for integrating moral issues in health technology assessment. Int J Technol Assess Health Care 2005;21(3):312-18.

17. Campbell E, Ross LF. Parental attitudes regarding newborn screening of PKU and DMD. Am J Med Genet A 2003;120(2):209-14.

Received: February 13, 2006

Accepted: November 6, 2006 